\title{
FRANGOS DE CORTE DE LINHAGENS PESCOÇO PELADO E CARIJÓ, CRIADOS SOB CONDIÇÕES DE ESTRESSE TÉRMICO - REVISÃO DE LITERATURA
}

\author{
Angela Maria Fortes de Andrade ${ }^{1}$ \\ Marcelo Bastos Cordeiro ${ }^{3}$ \\ Henrique Jorge de Freitas ${ }^{2}$ \\ Reginaldo da Silva Francisco ${ }^{4}$
}

\begin{abstract}
ANDRADE, A. M. F. de; CORDEIRO, M. B.; FREITAS, H. J. de; FRANCISCO, R. da S. Frangos de corte de linhagem Pescoço Pelado e Carijó, criados sob condições de estresse térmico - revisão de literatura. Arq. Ciênc. Vet. Zool. UNIPAR, Umuarama, v. 22, n. 4, p. 119-125, out./dez. 2019.
\end{abstract}

RESUMO: O Brasil tem situação vantajosa relacionada às condições de acondicionamento das aves em relação a outros países. A evolução nas áreas de genética, nutrição e manejo das aves tem possibilitado a obtenção de produtos de baixo custo e de alta qualidade, proporcionando maior competitividade no mercado. O Brasil caracteriza-se por ser um país predominantemente agrícola, porém é um país tropical que apresenta altas temperaturas e estas por sua vez, influenciam diretamente no bem-estar das aves. A produção de frango de corte em regiões de clima quente, a exemplo do Acre, precisa ser considerada, pois apresentam condições climáticas diferenciadas, o que pode exercer uma influencia negativa nos resultados de desempenho animal, como resposta ao clima e ambiente de criação, portanto, este estudo de revisão de literatura objetivou analisar estudos inerentes às condições de conforto térmico ambiental e respostas fisiológicas e zootécnicas em frangos de corte criados em clima de verão amazônico.

PALAVRAS-CHAVE: Ambiência. Avicultura. Verão Amazônico.

\section{NAKED NECK AND CALIFORNIA GRAY BROILER CHICKEN REARED UNDER THERMAL STRESS CONDITIONS - LITERATURE REVIEW}

\begin{abstract}
Brazil is at an advantageous position regarding the storage conditions of poultry in relation to other countries. The evolution in genetics, nutrition and bird management has made it possible to obtain low-cost, high quality products and provide greater competitiveness in the market. Brazil is a predominantly agricultural country, but it is a tropical country with high temperatures, which has direct influence on poultry welfare. The production of broiler chickens in states with hot climate, such as Acre, needs to be considered, since they have different climatic conditions that may exert a negative influence on the performance of animals as a response to the harsh climate and breeding environment. This literature review aimed at analyzing studies inherent to the conditions of environmental thermal comfort and physiological and zootechnical responses in broiler chickens reared in the Amazonian summer climate.
\end{abstract}

KEYWORDS: Ambience. Poultry Farming. Amazonian Summer.

\section{POLLOS DE ENGORDE DE ASCENDENCIA CUELLO DESNUDOS Y CARIJÓ CREADOS EN CONDICIONES DE ESTRÉS TÉRMICO - REVISIÓN DEL LITERATURA}

RESUMEN: Brasil tiene una situación ventajosa en relación a las condiciones de acondicionamiento de las aves en relación a otros países. Los avances en las áreas de genética, nutrición y manejo de las aves ha permitido la consecución de bajo costo y productos de alta calidad, proporcionando una mayor competitividad en el mercado. Brasil se caracteriza por ser un país predominantemente agrícola, pero es un país tropical con altas temperaturas y estas a su vez influyen directamente en el bienestar de las aves. La producción de pollos de engorde en regiones de climas calurosos, como el Acre, debe ser considerado, ya que tienen diferentes condiciones climáticas, que puede ejercer una influencia negativa en los resultados de rendimiento de los animales en respuesta al clima y medio ambiente de creación, por lo tanto, este estudio bibliográfico ha objetivado analizar estudios inherentes a las condiciones de conforto térmico ambiental y respuestas fisiológicas y zootécnicas en pollos de engorde creados en clima de verano amazónico.

PALABRAS CLAVE: Ambiente. Avicultura. Verano Amazónico.

\footnotetext{
DOI: $10.25110 /$ arqvet.v22i4.2019.6023

'Universidade Federal do Acre, Doutoranda em Sanidade e Produção Animal Sustentável na Amazônia Ocidental, Rio Branco - AC, angelamariafortes@ hotmail.com;

${ }^{3}$ Universidade Federal do Acre, Pesquisador Bolsista do Curso de Medicina Veterinária, Rio Branco - AC, mbcordeiro@gmail.com;

${ }^{2}$ Universidade Federal do Acre, Professor Doutor do Curso de Medicina Veterinária, Rio Branco - AC, henriqufac@ufac.br;

${ }^{4}$ Universidade Federal do Acre, Doutorando em Sanidade e Produção Animal Sustentável na Amazônia Ocidental, Rio Branco - AC, reginaldofco2011@ gmail.com;
} 


\section{Introdução}

A produção de frangos de corte na Amazônia Ocidental visa aumentar a geração de emprego e renda no campo diminuindo assim, o êxodo rural e funcionando como uma alternativa econômica de renda familiar e de aquisição de proteína animal.

Neste contexto, os avanços tecnológicos têm favorecido a eficiência na avicultura oferecendo condições de expansão e viabilidade desta atividade, além de que a avicultura é uma atividade sustentável, uma vez que favorece a utilização de áreas já degradadas diminuindo o impacto ambiental (EMBRAPA, 2015).

Devido ao emprego maciço de material genético oriundo de clima temperado, as aves têm capacidade responsiva melhor ao frio. As penas também influenciam nas perdas de calor, sendo um bom isolante térmico para o frio, mas não tão eficiente no estresse por calor (NASCIMENTO; SILVA, 2013).

O conforto térmico é definido pela sensação de bem-estar. De maneira geral, o ambiente pode ser considerado confortável para as aves adultas quando apresenta temperatura média de $21^{\circ} \mathrm{C}$ e umidade relativa do ar de 57 a $69 \%$ (SCHUTZ, 2011).

O clima ambiental amazônico possui uma alta temperatura durante todo ano sendo que, entre agosto e outubro são registradas as maiores elevações de temperaturas do ano, chegando aos $33^{\circ} \mathrm{C}$ (com variação de $29^{\circ} \mathrm{C} \mathrm{a} 31^{\circ} \mathrm{C}$ ) e umidade relativa do ar de $75 \%$ (variação diária de $55 \%$ a $87 \%$ ). São fatores que devem ser considerados na produção avícola da região a fim de que sejam oferecidas condições ambientais para a viabilização dessa atividade (ABREU; ABREU, 2011).

A faixa de conforto térmico das aves de corte encontra-se de $30^{\circ} \mathrm{C}$ a $32^{\circ} \mathrm{C}$ na primeira semana de vida, $28^{\circ} \mathrm{C}$ a $30^{\circ} \mathrm{C}$ na segunda semana de vida, $26^{\circ} \mathrm{C}$ a $27^{\circ} \mathrm{C}$ na terceira semana de vida e $23^{\circ} \mathrm{C}$ a $26^{\circ} \mathrm{C}$ na quarta semana de vida; a partir da quinta semana de vida o conforto térmico é dado por $20^{\circ} \mathrm{C}$ (CÂNDIDO et al., 2015). No ciclo final de vida, as aves entram em estresse térmico e podem sofrer uma grande depressão causada pela sensibilidade às altas temperaturas (OLIVEIRA et al. 2016).

Esta revisão objetivou buscar estudos sobre os efeitos do ambiente térmico em frangos de corte e sua influência no desempenho zootécnico em regiões de clima quente, a exemplo do Acre.

\section{Panorama da avicultura brasileira}

Nas últimas três décadas, a avicultura brasileira tem apresentado altos índices de crescimento. Seu bem principal, o frango, conquistou os mais exigentes mercados, tornando o país o segundo produtor mundial e líder em exportação, sendo que atualmente, a carne nacional chega a mais de 150 países (ABPA, 2018).

A avicultura emprega mais de 6,8 milhões de pessoas, direta e indiretamente, e responde por quase $2,5 \%$ do PIB (UBABEF, 2018). Atualmente, cerca de $70 \%$ da carne exportada no mundo tem origem no Brasil, sendo que a produção brasileira de carne de frango tem apresentado um significativo crescimento anual, alcançando uma produção no ano de 2017 de 13,05 milhões de toneladas de carne, dos quais $33,1 \%$ foi destinado à exportação (ABPA, 2018).
Dados coletados pela Associação Brasileira de Proteína Animal (ABPA) mostram que as exportações brasileiras de carne de frango (considerando frango inteiro, cortes, processados e salgados). As exportações brasileiras de carne de frango, totalizaram 2,433 milhões de toneladas entre janeiro de julho deste ano, informa a Associação Brasileira de Proteína Animal (ABPA). O dado é 5,8\% superior ao efetivado no mesmo período de 2018, quando foram embarcadas 2,3 milhões de toneladas (ABPA, 2019).

O Brasil tem situação vantajosa relacionada às condições de acondicionamento das aves em relação a outros países (ABREU; ABREU, 2011), contudo são necessários investimentos nos sistemas de acondicionamento, tornando-os compatíveis com a realidade climática e com o tipo de instalação avícola usado em cada região do Brasil (MENDES et al., 2004). Deste modo regiões com características climáticas extremas de temperatura e umidade, como é o exemplo do estado do Acre, exerce influência direta sobre o desempenho produtivo das aves, fazendo-se necessário trabalhar com acondicionamento nos galpões de produção.

Nesse contexto, a avaliação de diferentes linhagens de corte é fundamental para obtenção de dados atualizados acerca das características produtivas que melhor atendam às necessidades do mercado consumidor (MENDES, 2001; MOREIRA et al.,2003).

O grande desafio da ambiência é conseguir que o ambiente interno não seja agressivo ao animal ou trabalhadores e esteja sempre identificando futuras questões que possam vir a causar problemas produtivos, mesmo antes que estes comecem a existir (BAÊTA; SOUZA, 2010). Ambientes considerados quentes e úmidos, mesmo sem haver mortalidade, apresentaram redução em $67 \%$ no ganho de peso diário (BUSTAMANTE et al., 2013).

Assim, ao projetar as instalações para criação de aves deve-se pensar no acondicionamento térmico natural e seu aproveitamento nos meios naturais para melhorar as condições térmicas internas dos galpões onde as aves serão alojadas (VIEIRA et al., 2016).

Entre os efeitos do estresse calórico sofrido pelas aves, o mais comum é o aumento da frequência respiratória para estimular a perda evaporativa e manter o equilíbrio térmico corporal (FURLAN; MACARI, 2002).

Quando em temperaturas ambientais altas, as melhores ferramentas de dissipação de calor utilizadas pela ave são o aumento da taxa respiratória que é chamada de hiperventilação e a vasodilatação periférica que promove a perda não evaporativa (LAVOR et al., 2008).

Em situações de estresse térmico, além do aumento da temperatura cloacal das aves, também ocorre o aumento da frequência respiratória (ofegação), com consequente efeito no metabolismo para estimular a perda evaporativa de energia e manter o equilíbrio térmico corporal (YAHAV et al., 2005).

A termorregulação completa é alcançada quando as aves são capazes de manter uma temperatura corporal constante, mesmo que no ambiente ocorra variações de temperatura. As exigências térmicas mudam com a idade, sendo que o estresse pelo frio ocorre apenas nos pintos e nos adultos o estresse por calor (SCAHAW, 2000).

A temperatura média ideal para criação de frangos de corte está próxima aos $20{ }^{\circ} \mathrm{C}$ (MACARI; GONZALES, 
1990; COOPER; WASHBURN, 1998; TANKSON et al., 2001). Em variadas condições térmicas na criação de aves, os mecanismos de controles térmicos ambientais são indispensáveis, pois faixas de altos riscos significam perdas produtivas atingindo desde rendimento de carcaça, conversão alimentar até a mortalidade, decorrente, da exposição ao estresse calórico (TANKSON et al., 2001; NIENABER; HAHN, 2004; PEREIRA, 2012; SALGADO, 2006; VALE et al., 2008).

\section{Características das linhagens híbridas caipiras}

As aves são provenientes de criadores matrizeiros que fazem cruzamentos industriais específicos, apresentando média de velocidade de crescimento, alta rusticidade e boa adaptabilidade (BRAGA; ROQUE, 2008; CAIRES et al., 2010).

A característica da linhagem utilizada na criação de frango caipira pescoço pelado (Label Rouge) é de crescimento lento, coloração mista, aptidão para produção de carne, apresentando pele fina de cor amarela, bico e patas de cor amarela forte, e sua carne é mais rígida e pode ser abatida até aos 90 dias com um peso médio de 2,5 quilos (SAVINO et al., 2007; CAIRES et al., 2010).

Souza et al. (2012), descrevem que o frango de corte tipo caipira carijó é de linhagem híbrida, possui crescimento rápido e apresenta penas pretas com pontos brancos por todo o corpo, possuindo porte alto com canelas longas, bicos e patas de cor amarela.

Observando as características destas aves Takahashi et al. (2006) trabalharam com linhagens coloniais (Pescoço Pelado e Carijó), confinadas e verificaram que os desempenhos das aves não foram afetados pelo sistema de produção. Entretanto, compararam as linhagens, observaram que a $\mathrm{Ca}-$ rijó apresentou melhor desempenho e rendimento de carcaça. E concluíram que as linhagens selecionadas devem ser consideradas para melhor rendimento na produção e aumentar a eficiência da criação avícola colonial. Assim, o conhecimento das características genéticas e da relação entre os atributos da carne e outras características de interesse em frangos de corte caipira pode favorecer o estabelecimento mais preciso e adequado das estratégias utilizadas nos programas de seleção (LUPATINI et al., 2015).

A avaliação dos genótipos comerciais disponíveis no mercado para criação e a informações relacionadas ao crescimento, desempenho, rendimento e qualidade da carcaça desses genótipos são importantes para o aumento da lucratividade na produção (DOURADO et al., 2009). Portanto para atender a necessidade de cada linhagem tem-se que observar os fatores que interferem direta e indiretamente nesta atividade, os parâmetros produtivos, como melhoramento genético, manejo nutricional e sanitário, ambiência e bem-estar animal (OLANREWAJU et al., 2016; DEEP et al., 2018).

\section{Características climáticas do estado do Acre e o desempe- nho zootécnico das aves}

O Estado do Acre está localizado na Amazônia Ocidental, apresenta clima do tipo equatorial, quente e úmido, caracterizado por altas temperaturas, elevados índices de precipitação pluviométrica e alta umidade relativa do ar (SOUZA et al., 2016).

A temperatura média anual está em torno de $24,5^{\circ} \mathrm{C}$, enquanto a máxima fica em aproximadamente $33{ }^{\circ} \mathrm{C}$, uniforme para todo o estado (ACRE, 2018). A região acreana possui duas estações climáticas bem definidas (seca e chuvosa), o período de inverno corresponde aos meses de outubro a abril, é a época de chuvas e a umidade relativa do ar alta, com média de $88 \%$ e oscilação diária variando de $55 \%$ a $98 \%$ (DUARTE, 2005).

Em países tropicais, altas temperaturas influenciam diretamente no bem-estar das aves proporcionando pouca margem de manobra, sendo que os fatores climáticos são pobremente manipulados e gerenciados, para a manutenção da homeostase térmica (BERAQUET, 2000).

O verão corresponde ao período da seca (verão amazônico, que geralmente ocorre entre os meses de maio e setembro) a umidade relativa média do ar é de $75 \%$ e a variação diária fica entre $50 \%$ e $87 \%$. Sendo as maiores temperaturas do ano entre junho a agosto, apresentando a máxima entre $33{ }^{\circ} \mathrm{C}$ com média anual entre $29{ }^{\circ} \mathrm{C}$ a $33{ }^{\circ} \mathrm{C}$, sendo os meses de transição maio e setembro (DUARTE, 2016).

As características climáticas do Acre precisam ser consideradas, pois as aves são animais homeotermos, necessitando de temperaturas ideais que favoreçam seu desempenho fisiológico e zootécnico. As aves na fase inicial da vida são mantidas sob condições térmicas de conforto, portanto mais ativas em relação às aves mais velhas e que condições adversas de temperatura afetam esse comportamento (CORDEIRO et al., 2011). Dessa forma, a características climáticas do verão amazônico e a escolha de linhagens de frango caipira para produção avícola deve ser um fator a ser considerado para otimizar a produção.

\section{Fatores ambientais que afetam o conforto animal}

\section{Temperatura}

No Brasil, em regiões tropicais a exemplo do Acre, durante quase todo ano, a temperatura ambiente, a intensidade de radiação solar e umidade do ar são muito elevadas. Assim, ao projetar as instalações para criação de aves deve-se pensar no acondicionamento térmico e seu aproveitamento nos meios naturais para melhorar as condições térmicas internas dos galpões onde as aves serão alojadas (ACRE, 2018).

As características climáticas do Acre precisam ser consideradas, pois as aves são animais homeotermos, necessitando de temperaturas ideais que favoreçam seu desempenho fisiológico e zootécnico. Em climas tropicais as elevadas temperaturas ambientais e os altos índices de umidade relativa do ar, principalmente no verão, geram condições de estresse térmico na produção avícola e interfere no desempenho zootécnico, constituindo um dos principais problemas em condições de confinamento (SOUZA, 2015).

Segundo Pereira et al. (2011), o ambiente físico no qual a ave está inserida é composto pelo ambiente térmico, aéreo, físico, biológico, acústico e social e suas interações, sendo estas difíceis de serem mensuradas com precisão. Entre os efeitos do estresse calórico sofrido pelas aves, o mais comum é o aumento da frequência respiratória para estimular a perda evaporativa e manter o equilíbrio térmico corporal (FURLAN, MACARI, GONZALES, 2002).

Segundo Nascimento (2010), as aves perdem até $80 \%$ do calor por meio dos mecanismos de radiação, convec- 
ção e condução, no entanto, em um ambiente onde a temperatura do ar se aproxima da temperatura da pele do animal, o mecanismo principal de perda de calor passa a ser o processo de evaporação da água pelo trato respiratório.

Segundo Dinten (2005), dentre os fatores ambientais que afetam o conforto das aves estão a temperatura, a ventilação, a iluminação e a umidade. Os efeitos conjuntos das temperaturas elevadas e ventilação deficiente são os fatores que mais interferem na elevação do estresse em frangos de corte.

O melhor indicador das condições de conforto térmico em um ambiente de criação é o próprio comportamento do animal, pois a alteração do mesmo indica a necessidade de adequação das condições térmicas do sistema de aquecimento ou resfriamento do ambiente (SCHIASSI et al.,2016). Aglomerações podem indicar necessidade de melhor aquecimento, já espaços vazios e/ou bicos abertos, aumento da taxa respiratória, pescoços e asas estendidas indicam altas temperaturas no ambiente (ABREU, 2002). Para que as aves tenham mínima fração de energia utilizada para manter sua temperatura corporal e máxima utilização para produção, é necessário que permaneçam em conforto térmico (DALÓLIO et al., 2015).

Segundo Pereira et al. (2011), o ambiente físico no qual a ave está inserida é composto pelo ambiente térmico, aéreo, físico, biológico, acústico e social e suas interações, sendo estas difíceis de serem mensuradas com precisão. Baêta e Souza (2010) descrevem os constituintes do ambiente térmico como sendo a temperatura, a umidade, a radiação e o vento.

Em variadas condições térmicas na criação de aves, os mecanismos de controle térmico ambiental são indispensáveis, pois faixas de altos riscos significam perdas produtivas atingindo desde o rendimento de carcaça, conversão alimentar até a mortalidade, decorrente, da exposição ao estresse calórico (VALE et al., 2008). O sucesso na criação de frango de corte, tem características de desempenho importantes do híbrido comercial como, ganho de peso, eficiência alimentar que contribuirão na viabilidade e o desempenho dos rendimentos de carcaça, uma vez que as seleções das linhagens utilizadas colaboram para melhor viabilidade econômica. (SOUZA, 2015).

Deste modo regiões com características climáticas extremas de temperatura e umidade, como é o exemplo do estado do Acre, exerce influência direta sobre o desempenho produtivo das aves. Assim, considerando que aves de linhagens caipira apresentam condições fisiológicas diferenciadas, o produtor pode utilizar linhagens com características rústicas e maior resistência às adversidades climáticas.

\section{Umidade Relativa}

Sandre (2016), afirma que o valor de umidade relativa do ar não deve ultrapassar $80 \%$, a fim de que não comprometa a perda de calor das aves pela via evaporativa. A capacidade das aves de suportar o calor é inversamente proporcional ao teor de umidade relativa do ar. Quanto maior a umidade relativa do ar, mais dificuldade a ave terá para eliminar o calor interno através das vias aéreas, aumentando assim a frequência respiratória (OLIVEIRA et al., 2011).

Segundo Teixeira (2012), ambientes com umidade relativa elevada, além de reduzir o processo evaporativo de dissipação de calor, umedece a cama aviária, contribuindo com a proliferação de microrganismos patogênicos e favorece o aparecimento de doenças.

O teor de umidade da cama nos aviários é uma variável relacionada às características de criação como, dieta utilizada, consumo hídrico das aves, temperatura ambiente, ventilação e tipo de bebedouro utilizado, sendo que este último apresenta como um fator de grande relevância (OLIVEIRA et al., 2004). Sendo assim, faz-se necessário o uso de tecnologias para reduzir a emissão de amônia, de odores e teores de umidade ao longo da criação de frangos de corte.

A utilização da ventilação mínima objetivando a manutenção adequada da temperatura e da umidade relativa ao nível correto permite a troca de ar, o que garante um adequado fornecimento de oxigênio e remoção de gases nocivos e manutenção da cama em boas condições (MENEGALI et al, 2013). O ar é fonte de oxigênio para o metabolismo de qualquer espécie animal, funciona como um excelente veículo de dissipação do calor excedente, vapor de água, gases provenientes dos animais e da decomposição dos dejetos, além de dissipar a poeira liberada pela cama (VIEIRA et al., 2016).

Salgado et al. (2010) afirmam que a distribuição de poluentes aéreos nas instalações para criação de animais depende também da tipologia do abrigo, do local de entrada e saída do ar, do fluxo de ar e do padrão de circulação interno do ar, sendo que a mensuração da taxa de ventilação é tida como requisito fundamental nestes estudos.

Cony e Zocche (2004) relataram que a ventilação é necessária até mesmo durante o período de aquecimento, a fim de promover troca de ar suficiente para evitar o acúmulo de gases prejudiciais, tais como $\mathrm{CO}_{2}, \mathrm{CO}$ e $\mathrm{NH}_{3}$. A ventilação de verão é designada para as aves referentes às exigências de necessidade higiênica e térmica. Sob condições de temperaturas elevadas, o movimento do ar é essencial para a melhoria das condições ambientais, atuando de maneiras distintas, sendo por convecção, se a temperatura ambiente estiver abaixo da temperatura corporal da ave, por evaporação favorecendo a troca de calor e por dissipação, levando o calor evaporado pela respiração. Além disso, atua na sensação térmica de calor, reduzindo a temperatura efetiva sentida pelas aves (VIEIRA, 2016).

Em situações em que a ventilação natural não é suficiente para a manutenção ideal das condições climáticas (temperatura e umidade relativa) no interior dos aviários, utiliza-se a ventilação mecânica ou artificial. Existem duas formas de se promover artificialmente a movimentação do ar em aviários: Sistema de pressão positiva ou pressurização, com uso de ventiladores e sistema de pressão negativa ou exaustão com uso de exaustores. Neste caso é utilizada a ventilação mínima ou ventilação higiênica, definida por Barnwell e Wilson (2005), como a quantidade mínima de troca de ar exigida para manter o ambiente da instalação avícola em condições adequadas à saúde, bem-estar e eficiência produtiva das aves.

Neste sentido, alguns índices como a exemplo o do Índice de temperatura de globo negro-ITGU, e o da Entalpia$\mathrm{H}^{\mathrm{o}}$, que analisa a termodinâmica que envolvem as trocas de calor, entre o sistema e o meio ambiente externo mensurados a partir dos valores de temperatura do ar e de umidade relativa, sendo empregados para avaliar as características biocli- 
máticas das instalações para aves, afim de identificar sua efetividade na manutenção do conforto térmico (MEDEIROS et al., 2005; MENEGALI et al., 2013; ROCHA et al., 2010).

Assim sendo, a produtividade satisfatória dos frangos depende das condições térmicas do ambiente de alojamento, que refletem a combinação dos efeitos da temperatura de bulbo seco, da umidade relativa, da radiação solar incidente e da velocidade do ar a que a ave está submetida (GARCIA et al., 2012).

Portanto, o sucesso da produção avícola depende, entre outros fatores, da redução dos efeitos climáticos indesejáveis sobre os animais, sendo necessário, portanto, a caracterização do ambiente térmico.

\section{Considerações Finais}

Considerando os aspectos abordados no que diz respeito à produção de aves em clima quente, observou-se que algumas condições de criação são inadequadas para regiões de temperaturas elevadas.

Portanto, a melhoria das condições ambientais dentro das instalações, aliadas à escolha de linhagens melhor adaptadas às condições de climas tropicais é pautada como solução para que os animais produzam com eficiência. Assim, o grande desafio da ambiência é melhorar o ambiente interno de modo que este não seja agressivo ao animal, além de identificar futuras questões que possam vir a incidir negativamente nos índices produtivos.

No estado do Acre há um crescimento efetivo na produção avícola apontando para o fortalecimento da agricultura familiar rural da região. Para tanto se faz necessário buscar estudos que avalie efeitos do ambiente térmico avícola e sua influência no desempenho zootécnico em regiões de clima quente, a exemplo do Acre.

\section{Referências}

Associação Brasileira de Proteína Animal. ABPA: Relatório anual de 2018. Disponível em: http://abpa-. Disponível em: http://abpa-br.com.br/noticia/exportacoes-de-carne-defrango-mantem-alta-de-58-em-2019-2861. Acesso em: 23 nov. 2019

ABREU, V. M. N.; ABREU, P. G. Os desafios da ambiência os sistemas de criação de aves no Brasil. Revista Brasileira de Zootecnia, v. 40, p. 1-14, 2011.

ABREU, V. M. N. Produtividade e bem-estar. Avicultura Industrial, Porto Feliz, ano 93, n. 8, p. 26-38, edição 1121, 2002 .

ACRE. Secretaria de Estado de Meio Ambiente. Plano estadual de recursos hídricos do Acre. Rio Branco: SEMA, p. $356,2012$.

BAÊTA, F. C.; SOUZA, C. F. Ambiência em edificações rurais: conforto animal. Viçosa, UFV, p. 268, 2010.

BARNWELL, B.; WILSON, M. Importance of minimum ventilation. Techinical Focul Cobb, v. 1, 2005.
BERAQUET, N. J. Influência de fatores ante pós mortem na qualidade da carne de aves. Revista Brasileira de Ciência Avícola, v. 1, n. 3, p. 155-166,2000.

BRAGA, R. M.; ROQUE, M. S. Comercialização de galinha viva do tipo "caipira" em Boa Vista, Roraima, 2008. Boa Vista-R: Embrapa Roraima, 2008. 18p.

BUSTAMANTE, E. Exploring ventilation efficiency in poultry buildings: The validation of computational fluid dynamics (CFD) in a cross-me chanically ventilated broiler farm. Energies, Singapura, v.6, p.2605-2623, abril 2013.

CAIRES, C. M.; CARVAlHO, A. P.; CAIRES, R. M. Criação alternativa de frangos de corte. Artigo 106. Revista Eletrônica Nutritime, v. 7, n. 2, p. 1169-1174, 2010.

CÂNDIDO, M. G. L. Determinação da faixa de conforto térmico com base nos resultados de desempenho produtivo e respostas fisiológicas de frangos de corte submetidos a diferentes ambientes térmicos durante a fase inicial de criação. 2015. 58f. Dissertação (Mestrado em Engenharia Agrícola) - Universidade Federal de Viçosa, viçosa, MG. 2015.

CONY, A. V.; ZOCCHE, A. T. Manejo de frango de corte. In: MENDES, A. A.; NÃ̃̃S, I. A.; MACARI, M. (Eds.). Produção de frangos de corte. Campinas, SP: Facta, 2004, p. 117-136.

COOPER, M. A.; WASHBURN, K. W. The relationships of body temperature to weight gain, feed consumption, and feed utilization in broilers under heat stress. Poultry Science, Stanford, v. 77, n. 2, p. 237-242, 1998.

CORDEIRO, M. B. et al. Análise de imagens digitais para avaliação do comportamento de pintinhos de corte. Revista de Engenharia Agrícola, Jaboticabal, v, 31, n. 3, 2011. p. 418-426.

DALÓLIO, F. S. et al. Heat stress and vitamin E in diets for broilers as a mitigating measure. Acta Scientiarum. Animal Sciences, Maringá, v. 37, n .4, p. 419-427, 2015.

DEEP, A. et al. Effect of light intensity on broiler production, processing characteristics and welfare. Poultry Science, v. 89, p. 2326-2333, 2018.

DINTEN, C. A. M. O trabalho na avicultura de corte: organização, tecnologia e resultados da produção. 2005. 234f. Tese (Doutorado em Engenharia Agrícola). Universidade Estadual de Campinas, Campinas, SP, 2005.

DOURADO, L. R. B. et al. Crescimento e desempenho de linhagens de aves pescoço pelado criadas em sistema semiconfinado. Ciência Agrotécnica, Lavras, v. 33, n. 3, p. 875881, maio/jun., 2009.

DUARTE, A. F. Aspectos da climatologia do Acre, Brasil, com base no intervalo 1971 - 2000. Revista Brasileira de Meteorologia, São Paulo, v. 21, n. 3b, 2018. p. 96-105. 
Duarte, A. F. Variabilidade e tendência das chuvas em Rio Branco, Acre, Brasil. Revista Brasileira de Meteorologia, v.20, n.1, 2005. p.37-42.

EMBRAPA. Frango de Corte tem Árvore do Conhecimento. Disponível em: http://www.embrapa.br/imprensa/ noticias/2015/setembro/1 a-semana/frango-decorte-temarvore-do-conhecimento/. Acesso em: 20 Novembro de 2018.

FONSECA, R. A. et al. Avaliação de linhagens de aves de corte tipo Caipira submetidas ao bioclima do litoral do Paraná. Scientia Rural, p. 49-63, 2010.

FURLAN, R. L.; MACARI, M. Termorregulação. In: MACARI, M.; FURLAN, R. L.; GONZALES, E. Fisiologia aviária aplicada a frangos de corte. 2.ed. Jaboticabal: FUNEP/ UNESP, cap. 17, p. 209-230. 2002.

GARCIA, R. G. et al. Selecting the most adequate bedding material for broiler production in Brazil. Revista Brasileira de Ciência Avícola, Campinas, v.14, n.2, p.71-158, 2012

LAVOR, C. T. B.; FERNANDES, A. A. O.; SOUSA, F. M. Efeito de materiais isolantes térmicos em aviários no desempenho de frango de corte. Ciência Rural, Fortaleza, v. 39, n. 2, p. 308-316, Abr/jun. 2008.

LUPATINI, F. Avaliação do efeito de variáveis produtivas na conversão alimentar de frangos de corte. 2015. 58f. Dissertação (mestrado em Zootecnia) - Universidade Federal de Goiás, Goiânia, GO, 2015.

MACARI, M.; GONZALES, E. Fisiopatogenia da síndrome da morte súbita em frangos de corte. In: conferência apinco de ciência e tecnologia avícolas, 1990, Campinas. Anais... Campinas: Apinco, 1990. p.65-73.

MEDEIROS, C. M. et al. Índice térmico ambiental de produtividade para frangos de corte. Revista Brasileira de Engenharia Agrícola e Ambiental, Campina Grande, v. 9, n. 4 , p. 660-665, 2005.

MENEGALI, I. et al. Comportamento de variáveis climáticas em sistemas de ventilação mínima para produção de pintos de corte. Revista Brasileira. Engenharia. Agrícola. Ambiência, v.17, p. 106-113, 2013.

MENDES, A. A. Jejum Pré-abate em Frangos de Corte. Revista Brasileira de Ciência Avícola, v. 3, n. 3, p. 199 209, 2001.

MENDES, A. A. et al. Produção de frango de corte. Campinas: FACTA, p. 356, 2004.

MOREIRA, J. et al. Avaliação de desempenho, rendimento de carcaça e qualidade da carne do peito em frangos de linhagens de conformação versus convencionais. Revista Brasileira de Zootecnia, v. 32, n. 6, p. 1663-1673, 2003.

NASCIMENTO, S. T. Determinação do balanço de calor em frangos de corte por meio das temperaturas corporais. 2010. 147f. Dissertação (Mestrado em Física do ambiente agrícola) - Universidade de São Paulo, Piracicaba, SP, 2010.

NASCIMENTO, S. T.; SILVA, E. J. O. As perdas de calor das aves: entendendo as trocas de calor com o meio, 2013. Disponível em: http://www.avisite.com.br/cet/ img/20100916 trocasdecalor.pdf. Acesso em: 20 nov. 2018.

KHAMMAR, F.; AMIRAT, Z. Annual reproductive cycles in the endocrine activity of testis and ovary in some Algerian breeds of sheep and goats. In: INTERNATIONAL CONGRESS ON ANIMAL REPRODUCTION, 13., 1996, Sydney. Proceedings [...] Sydney: ISAR, 1996. v. 2, p. 1-22.

OLANREWAJU, H. A. J. P. et al. A review of lighting programs for broiler production. International Journal of Poultry Science, v. 5, p. 301-308, 2016.

OLIVEIRA, P. M.; FARIA JÚNIOR, M. J. A.; GARCIA NETO, M. Estratégias para minimizar os efeitos de um ambiente térmico adverso para frangos de corte. Arquivo Brasileiro Medicina Veterinária e Zootecnia, p. 739-747, 2016.

OLIVEIRA, R. F. M. et al. Efeitos da temperatura e da umidade relativa sobre o desempenho e o rendimento de cortes nobres de frango de corte de 1 a 49 dias de idade. Revista Brasileira de Zootecnia, v. 35, n. 3, p. 797-803, 2011.

OLIVEIRA, M. C.; MENDONÇA FILHO, P. R.; CARVALHO, I. D. Rendimento e lesões de carcaça de frangos de corte sexados criados em diferentes densidades populacionais. Ars Veterinária, Jaboticabal, v. 20, n. 1, p. 16-21, 2004.

PEREIRA, D. F.; OLIVEIRA, S. C.; PENHA, N. L. J. Logistic regression to estimate the welfare of broiler breeders in relation to environmental and behavioral variables. Engenharia Agrícola (Impresso), v. 31, p. 33 - 40, 2011.

PEREIRA, A. K. Fatores térmicos ambientais e qualidade do ar no desempenho produtivo de frango de corte criados em alta densidade sob sistema de ventilação positiva. 2006. 76 f. Dissertação (Mestrado em Engenharia Agrícola), Universidade Federal de Viçosa, Viçosa, MG. 2012.

ROCHA, H. P. et al. Índices Bioclimáticos e Produtivos em Diferentes Galpões Avícolas no Semiárido Paraibano. Revista Brasileira de Engenharia Agrícola e Ambiental, Campina Grande, v. 14, n. 12, p. 1330-1336, 2010.

SALGADO, D. D. Modelo estatístico para predição de bem-estar de reprodutoras de frango de corte baseado em dados de ambiente e análise do comportamento. 2006. 126 f. Dissertação (Mestrado em Construções Rurais e Ambiência) - Universidade Estadual de Campinas, Campinas, SP, 2006. 
térmico agudo ou crônico. 2016. 50f. Dissertação (Mestrado em Ciência Animal) - Universidade Estadual Paulista, Araçatuba, SP, 2016.

SALGADO, D. D.; NÄÄS, I. A. Avaliação de risco à produção de frangos de corte do estado de São Paulo em função da temperatura ambiente. Revista Engenharia Agrícola, v.30, p.367-376, 2010.

SAVINO, V. J. M. et al. Avaliação de materiais genéticos visando à produção de frango caipira em diferentes sistemas de alimentação. Revista Brasileira de Zootecnia, v.36, n.3, p.578-583, 2007.

SCAHAW. Comitê científico veterinário para saúde e bem-estar animal. European Comission. 2000. Disponível em: http://ec.europa.eu/food/fs/sc/scah/out39_en.pdf. Acesso em: 20 set. 2019.

SILVA, M. A. N. et al. Resistência ao estresse calórico em frangos de corte de Pescoço Pelado. Revista Brasileira de Ciência Avícola, Campinas, v. 3, n. 1, p. 27-33, jan. 2001.

SOUZA, M. C. M.; CERDAN, C. Sinais distintivos de origem e qualidade para produção de aves caipiras no Brasil e na França: os casos da indicação geográfica, do label rouge e da certificação orgânica. Informações Econômicas, São Paulo, v. 42, n. 2, p. 22-36, 2012.

SOUZA, B. B.; BATISTA, N. L. Os efeitos do estresse térmico sobre a fisiologia animal. Agropecuária Científica Semiárido, v.8, p.6-10, 2015.

SOUZA, E. B. et al. Sazonalidade da Precipitação sobre a Amazônia Legal Brasileira: Clima Atual e Projeções Futuras usando o modelo REGCM4 (Seasonal precipitation over the brazilian legal amazon: climate current and future projections using regcm 4 model). Revista Brasileira de Climatologia, v. 18, 2016.

SCHÜTZ, E. S. Variabilidade do ambiente térmico em galpão para frango de corte e sua influência nas respostas fisiológicas e comportamento das aves. 2011. 72f. Dissertação (Mestrado em Ciência Animal) - Universidade Federal de Goiás - UFG, Goiânia, GO.

SCHIASSI, L. et al. Análise do comportamento de frangos de corte submetidos a diferentes ambientes térmicos. Engenharia Agrícola, v. 35, n. 3, 2016.

TAKAHASHI, S. E. et al. Efeito do sistema de criação sobre o desempenho e rendimento de carcaça de frangos de corte tipo colonial. Arquivo Brasileiro de Medicina Veterinária e Zootecnia, v. 58, n. 4, p. 624-632, 2006.

TANKSON, J. D. et al. Stress and nutritional quality of broilers. Poultry Science, Stanford, v. 80, n. 9, p. 1.384$1.389,2001$

TEIXEIRA, A. H. C. et al. Aptidão agroclimática da cultura da videira no Estado da Bahia, Brasil. Revista Brasileira de Engenharia Agrícola e Ambiental, v.6, n.1, p.107-111, 2012.

UNIÃO BRASILEIRA DE AVICULTURA - UBABEF. A indústria avícola. Disponível em: http://www. brazilianchicken.com.br/. Acesso em 20 de novembro de 2019.

VALE, M. M. et al. Data mining to estimate broiler mortality when exposed to heat wave. Scientia Agrícola, Piracicaba, v.65, n.3, p.223-229, 2008.

VIEIRA, F. M. C. et al. The influence of thermal conditions from an environmentally controlled preslaughter lairage on mortality of broiler chickens. Arquivo Brasileiro de Medicina Veterinária e Zootecnia, v. 68, n. 2, p. 475-482, 2016.

VIEIRA, F. M. C. et al. Thermoregulation of day-old chickens submitted to simulated transport thermal environment. Arquivo Brasileiro de Medicina Veterinária e Zootecnia, v. 68 , n. 1, p. 208-214, 2016.

YAHAV, S. et al. Sensible heat loss: the broiler's paradox. World's Poultry Science Journal, v. 61, p. 419-434, 2005.

Recebido em: 11.02.2017 Aceito em: 28.12.2019 